\title{
Are double translocations double trouble?
}

\author{
S M BOWSER-RILEY*, M J GRIFFITHS*, M R CREASY ,
} P A FARNDON R A JOHNSON†, AND J L WATT*

From ${ }^{*}$ the Regional Cytogenetics Unit and $\ddagger$ the Clinical Genetics Unit, Birmingham Maternity Hospital, Edgbaston, Birmingham B15 2TG; and the Regional Cytogenetics Laboratory, East Birmingham Hospital, Birmingham B9 5ST.

SUMMARY Double translocation heterozygotes are rare, but need not necessarily pose more of a counselling problem than single reciprocal translocation heterozygotes. Nine cases of double translocation are presented, together with a review of the few reports published to date. An attempt is made to provide simple counselling guidelines in the assessment of the risk of producing a liveborn abnormal child. This is not based on theoretical considerations of segregation patterns, but extrapolated from what is known empirically about the viable segregation patterns in carriers of single reciprocal translocations. It assumes that there is no interference with the independent assortment of the two separate exchanges, unless a common participating chromosome is involved. The possibility of an interchromosomal effect has not been taken into consideration.

Translocations in man are found in one in 500 newborns, and with the main exceptions of the

Received for publication 24 June 1987. Accepted for publication 26 June 1987.
Robertsonian types and the $t(11 ; 22)$, the great majority are unique to a person or kindred. The presence of two independent translocations in one person is rare,$^{1-4}$ although three separate transloca-

TABLE 1 Brief clinical and cytogenetic details relating to the nine cases of double translocations.

\begin{tabular}{|c|c|c|c|c|}
\hline $\begin{array}{l}\text { Family and } \\
\text { pedigree No }\end{array}$ & Brief clinical details of index case & Cytogenetic result on index case & $\begin{array}{l}\text { Double translocation found in } \\
\text { family }\end{array}$ & Mode of ascertainment \\
\hline 1 & $\begin{array}{l}\text { Multiple malformations in one } \\
\text { week old female infant }\end{array}$ & $\begin{array}{l}\text { 46.XX. }-15,+\operatorname{der}(15), t(2 ; 15) \\
(\text { p23.2;q26.3) }\end{array}$ & $\begin{array}{l}\text { 45. XX.t(2:15)(p23.2:q26.3), } \\
\quad t(13 q 22 q)\end{array}$ & Unbalanced female mat \\
\hline 2 & $\begin{array}{l}\text { Multiple malformations in } 3 \text { week } \\
\text { old female infant }\end{array}$ & $\begin{array}{l}\text { 46, XX,t(3;14)(p13:q13) } \\
\quad-11,+\operatorname{der}(11), t(3 ; 11)(\mathrm{p} 25 ; \mathrm{q} 25)\end{array}$ & $\begin{array}{l}\text { 46.XX.t( }(3 ; 14)(\mathrm{pl} 3 ; \mathrm{q} 13) \\
\mathrm{t}(3 ; 11)(\mathrm{p} 25 ; \mathrm{q} 25)\end{array}$ & Unbalanced female mat \\
\hline 3 & $\begin{array}{l}\text { Symmetrical intrauterine growth } \\
\text { retardation detected on scan }\end{array}$ & $\begin{array}{l}\text { Amniotic fluid } 46 . \times X . t(7: 14) \\
\text { (p11.2:q13).t(11:12) } \\
(\text { p1 } 1 \cdot 2 ; q 13 \cdot 1)\end{array}$ & $\begin{array}{l}\text { 46.XX.t(7:14)(p11.2:q13). } \\
\quad t(11: 12)(p 11 \cdot 2: q 13 \cdot 1)\end{array}$ & $\begin{array}{l}\text { Growth retardation in utero+ } \\
\text { recurrent abortion. Balanced in } \\
\text { all liveborn }\end{array}$ \\
\hline 4 & Dysmorphic 10 year old boy & $\begin{array}{l}\text { 46.XY, }-13,+\operatorname{der}(13), t(13 ; 20) \\
(q 34 ; q 13 \cdot 1)\end{array}$ & $\begin{array}{l}\text { 46.XX.t }(4: 10)(422: q 25 \cdot 2) \text { also } \\
\text { seen in family. Double } \\
\text { hetcrozygote not seen }\end{array}$ & Unbalanced male mat \\
\hline 5 & $\begin{array}{l}32 \text { year old woman with history of } \\
3 \text { spontaneous abortions }\end{array}$ & $\begin{array}{l}\text { 46. XX.t( }(2: 3)(q 23 \text { or } q 31: q 27 \text { or } \\
q 29), t(5: 6)(q 35: p 21)\end{array}$ & $\begin{array}{l}\text { 46.XX.t( }(2: 3)(q 23 \text { or } q 31: q 27 \text { or } \\
q 29) \cdot t(5: 6)(q 3.35: p 21)\end{array}$ & ? Balanced female mat \\
\hline 6 & $\begin{array}{l}\text { Multiple malformations in } 2 \text { day } \\
\text { old male infant }\end{array}$ & $\begin{array}{l}\text { 45.XY.t(1:2)(p21-2:p13), } \\
-7 .-21,+\operatorname{der}(7) \cdot \mathrm{t}(7: 21) \\
(\mathrm{q} 36 \cdot 1: \mathrm{q} 22 \cdot 1)\end{array}$ & $\begin{array}{l}t(7: 21) \text { is family translocation. } \\
t(1: 2) \text { de novo in child }\end{array}$ & $\begin{array}{l}\text { Unbalanced male de novo for one } \\
\text { translocation }\end{array}$ \\
\hline 7 & $\begin{array}{l}6 \text { month old female with failure to } \\
\text { thrive }\end{array}$ & $\begin{array}{l}\text { 46.XX.t(6:14)(q15;q32), } \\
t(8 ; 12)(q 12 ; p 12)\end{array}$ & $\begin{array}{l}\text { 46.XX.t(6:14)(q15:q32), } \\
\quad 1(8: 12)(q 12: p 12)\end{array}$ & Balanced female not known \\
\hline 8 & Child with ambiguous genitalia & $\begin{array}{l}\text { 46.XY.dir ins }(13: 1)(\mathrm{q} 34 ; \\
\mathrm{p} 31 \cdot 2 \mathrm{p} 32 \cdot 3), \mathrm{t}(7 ; 12)(\mathrm{pl} 3 ; \mathrm{p} 13)\end{array}$ & Both translocations arose de novo & Balanced male de novo \\
\hline 9 & $\begin{array}{l}\text { Neonate with hydrocephalus and } \\
\text { congenital ocular abnormalities } \\
\text { (? HARD syndrome) }\end{array}$ & $46 . X \times . t(1 ; 2)(q 42 ; q 31 \cdot 3)$ & $\begin{array}{l}\text { 46.XX.t(1:2)(q42:q31-3),t(5:19) } \\
(p 11: q 13 \cdot 1)\end{array}$ & $\begin{array}{l}\text { Balanced female mat with } \\
\text { ? incidental abnormalities }\end{array}$ \\
\hline
\end{tabular}


tions have been reported. ${ }^{56}$ The majority of reports describing more than one translocation have indicated de novo origin of the rearrangements, but a few familial cases have been documented. ${ }^{7-10}$ There are no recorded cases of double translocations in the tenth listing of chromosome variants and anomalies in man. $^{11}$

We describe nine additional cases of double translocations and discuss the segregation patterns in the light of the available published reports. A few simple guidelines are suggested for use in counselling translocation families, especially where multiple translocations are segregating.

\section{Case reports}

Table 1 gives brief clinical details. Fig 1 illustrates pedigrees for families $1,2,3,4,5,6$, and 9 . No family information could be obtained in index case 7 and index case 8 had two de novo translocations.

\section{Materials and methods}

Blood cultures were established and harvested by standard methods, in later samples using thymidine block to achieve mitotic synchronisation ${ }^{12}$ and to facilitate early metaphase and prometaphase spreads. Amniotic fluid was cultured by a modification of a flask trypsinisation method, using Leighton tubes $(120 \times 16 \mathrm{~mm}){ }^{13}$

\section{Results}

Table 1 shows the karyotype in the index case and the double translocation found in the family, together with the mode of ascertainment.

\section{Discussion}

It is well documented that asymptomatic carriers of reciprocal translocations have variable reproductive

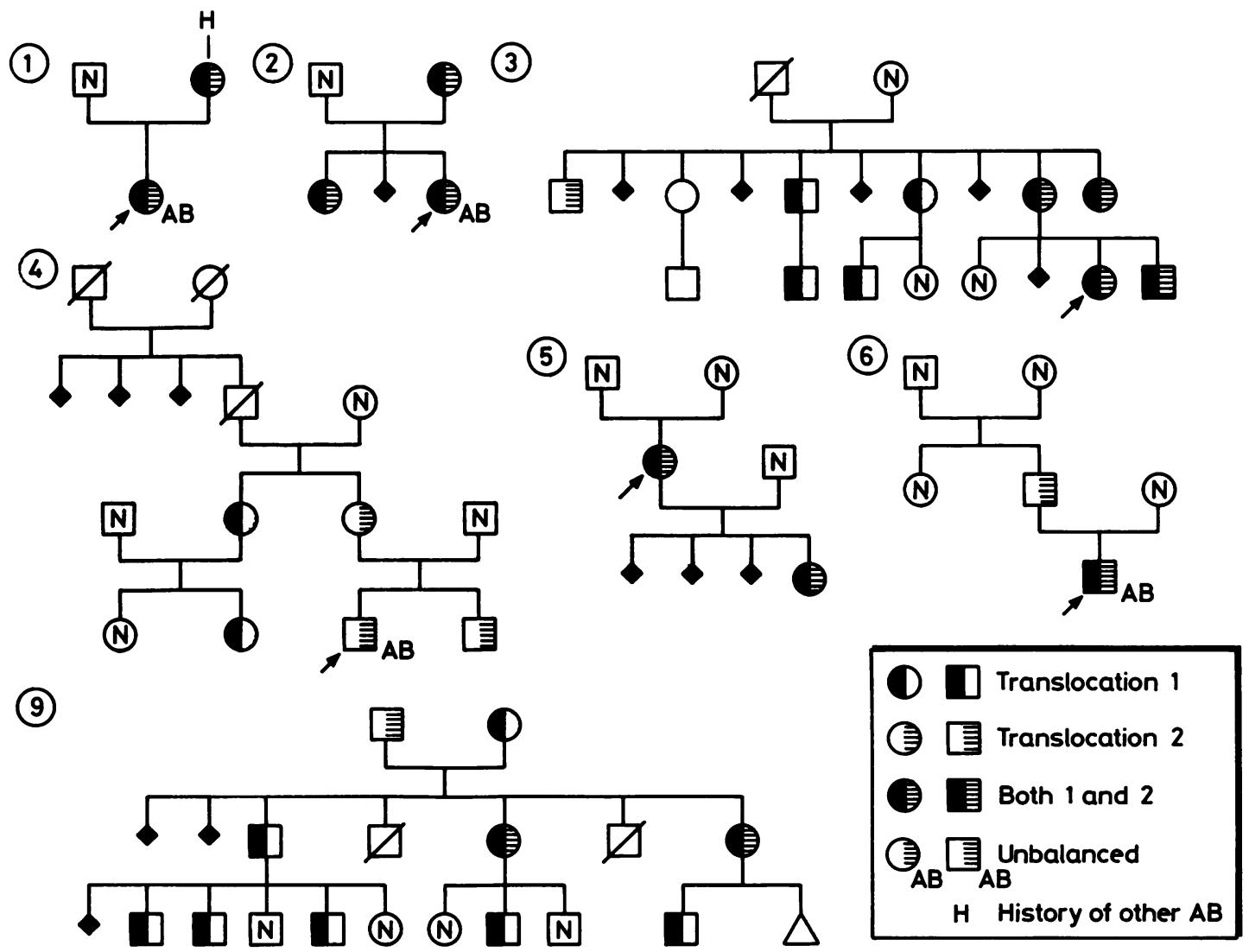

FIG 1 Pedigrees for families 1, 2, 3, 4, 5, 6, and 9. 
success. The theoretical types of alternate, adjacent, and 3:1 disjunction are already well documented ${ }^{14}$ and will not therefore be discussed in detail.

The consequences of the imbalance resulting from many of these theoretical possibilities are substantial, resulting in infertility or fetal wastage, but in certain cases the imbalance is comparatively slight and compatible with liveborn partial aneuploidy. All recorded cases of the latter result from adjacent 1 or 3:1 segregation.

Thus the empirical risk of producing one of these two types of a liveborn partial aneuploid child is much more important than the theoretical possibilities, particularly for counselling. Although the data on double translocation families are extremely limited, making a true empirical risk impossible, a reasonable estimate of risk of a liveborn abnormal child can be obtained by extrapolation from data on single translocation heterozygotes.

Several workers have produced useful data on single reciprocal translocations totalling almost 800 observations, ${ }^{15-20}$ but perhaps the largest and most useful series is the European collaborative study ${ }^{21}$ which details the prenatal observations in 1356 parental structural rearrangements, including 501 reciprocal translocations.

It is clear from the published reports that there is no available means of accurately predicting the risks of early miscarriage or viable abnormality in reciprocal translocation carriers, although the model by Davis et al $^{18}$ claims to predict the segregation mode with $87 \%$ accuracy and suggests that in certain cases potential viable aneuploidy can be completely dismissed. A computer program devised by de Arce et al $^{19}$ calculates the 16 types of unbalanced gametes, selects the least unbalanced, and obtains $98 \%$ of correct predictions. Again, if the predicted minimum imbalance is very large, this program can point out the impossibility of a viable, liveborn, abnormal reproductive outcome. The complexity of this available information is further compounded when we are trying to predict the reproductive

TABLE 2 The estimated percentage risk of liveborn abnormality for translocations excluding chromosomes 2, 3 , 12, 17, and 19. (If these chromosomes are involved, the risks can be further reduced in column $2^{*}$.)

\begin{tabular}{lll}
\hline & $\begin{array}{l}\text { Previous abnormal } \\
\text { liveborn }\end{array}$ & $\begin{array}{l}\text { Recurrent abortion } \\
\text { or other }\end{array}$ \\
\hline $\begin{array}{l}\text { Both exchanged segments } \\
\text { very small (<2 units) }\end{array}$ & $20 \%$ & $20 \%^{*}$ \\
$\begin{array}{l}\text { One of exchanged segments } \\
\text { very small (<2 units) }\end{array}$ & $20 \%$ & $10 \%^{*}$ \\
$\begin{array}{l}\text { Combined exchange }<12 \text { units } \\
\text { Combined exchange } \geqslant 12 \text { units }\end{array}$ & $\begin{array}{l}20 \% \\
\text { Unlikely }\end{array}$ & $5 \%^{*}$ \\
\hline
\end{tabular}

capacity in a person with two separate translocations.

These methods of prediction are perhaps unnecessarily complicated and cumbersome, considering that the rogue segregations leading to a liveborn abnormality are always an adjacent 1 or 3:1 type with a low threshold level of monosomy and a slightly higher threshold tolerance of concomitant trisomy.

The support for such a 'threshold' model comes from comparisons between families detected via an abnormal child and those referred for recurrent abortion which show that the size of the potential unbalanced segments is smaller where an abnormal child is the mode of ascertainment. ${ }^{17} 18$

Thus the size of the imbalance burden is of paramount importance and this is not irrespective of the chromosomes involved, since it has been clearly shown that the amount of tolerable trisomy and monosomy varies with the chromosome.

Boué and Gallano ${ }^{21}$ define one 'unit' as one band in a 300 band resolution karyotype and illustrate that the threshold of tolerance leading to a viable abnormal offspring is about 11 units, while spontaneous abortions are seen when up to 17 units are exchanged. No attempt has been made to assess separately the monosomy tolerance and the trisomy tolerance, but it has been shown that the overall size of the imbalance is directly proportional to the recurrence risk.

Chromosomes 4, 5, 9, 10, 11, 13, 18, 21, and 22 are over-represented in the liveborn observations while chromosomes 2, 3, 12, 17, and 19 are under-represented, indicating that the latter series

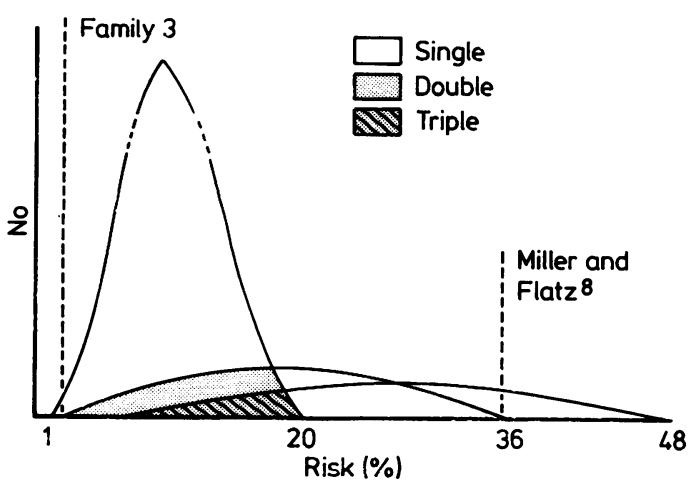

FIG 2 Diagramatic illustration of risk distribution curves for single (1 to $20 \%$ risk), double (1.99 to $36 \%$ ), and triple $(2.71$ to $48 \%)$ translocations. Note that the empirical risk in certain double and triple translocations overlaps the normal distribution curve for single translocations. 
TABLE 3 Risk estimates (of having a viable abnormal offspring) from each of the nime different double translocations. The units exchanged in each translocation are separately documented.

\begin{tabular}{|c|c|c|c|c|c|c|c|}
\hline \multirow[t]{2}{*}{ Family } & \multicolumn{2}{|c|}{ Translocation 1} & \multirow[t]{2}{*}{ Risk } & \multicolumn{2}{|c|}{ Translocation 2} & \multirow[t]{2}{*}{ Risk } & \multirow{2}{*}{$\begin{array}{l}\text { Combined empirical } \\
\text { risk estimation }(\%)\end{array}$} \\
\hline & Chrom $A$ & Chrom B & & Chrom C & Chrom D & & \\
\hline 1 & 3 & 1 & $20^{*}$ & 9 & 3 & 5 & 24 \\
\hline 2 & \multicolumn{7}{|c|}{ Omitted since there is a common chromosome involved in both translocations } \\
\hline 3 & 7 & 7 & 1 & 5 & 7 & 1 & 1.99 \\
\hline 4 & 1 & 1 & 20 & 12 & 2 & 1 & $20 \cdot 8$ \\
\hline 5 & 7 & 1 & 10 & 1 & 5 & 10 & 19 \\
\hline 6 & 8 & 9 & 1 & 1 & 1 & 20 & $20 \cdot 8$ \\
\hline 7 & $\begin{array}{l}9 \\
\text { (Insertion) }\end{array}$ & 1 & 10 & 6 & 2 & 5 & $14 \cdot 5$ \\
\hline 8 & 0 & 2 & 5 & 5 & 1 & 10 & $14 \cdot 5$ \\
\hline 9 & 3 & 7 & 5 & 3 & 1 & 10 & $14 \cdot 5$ \\
\hline $\begin{array}{l}\text { Miller and Flatz } \\
\text { t(3;19)(p25;q13) } \\
t(16 ; 22)(\mathrm{p} 13 ; \mathrm{q} 11)\end{array}$ & 2 & 1 & $20^{*}$ & 1 & 3 & $20^{*}$ & 36 \\
\hline
\end{tabular}

1 unit=1 band from 300 band haploid karyotype (ISCN 1978). Minimum units are recorded if breakpoints are in doubt, thus raximising risk. Bands containing breakpoints are included. Subdivisions of bands are ignored.

*Ascertained through previous abnormal liveborn.
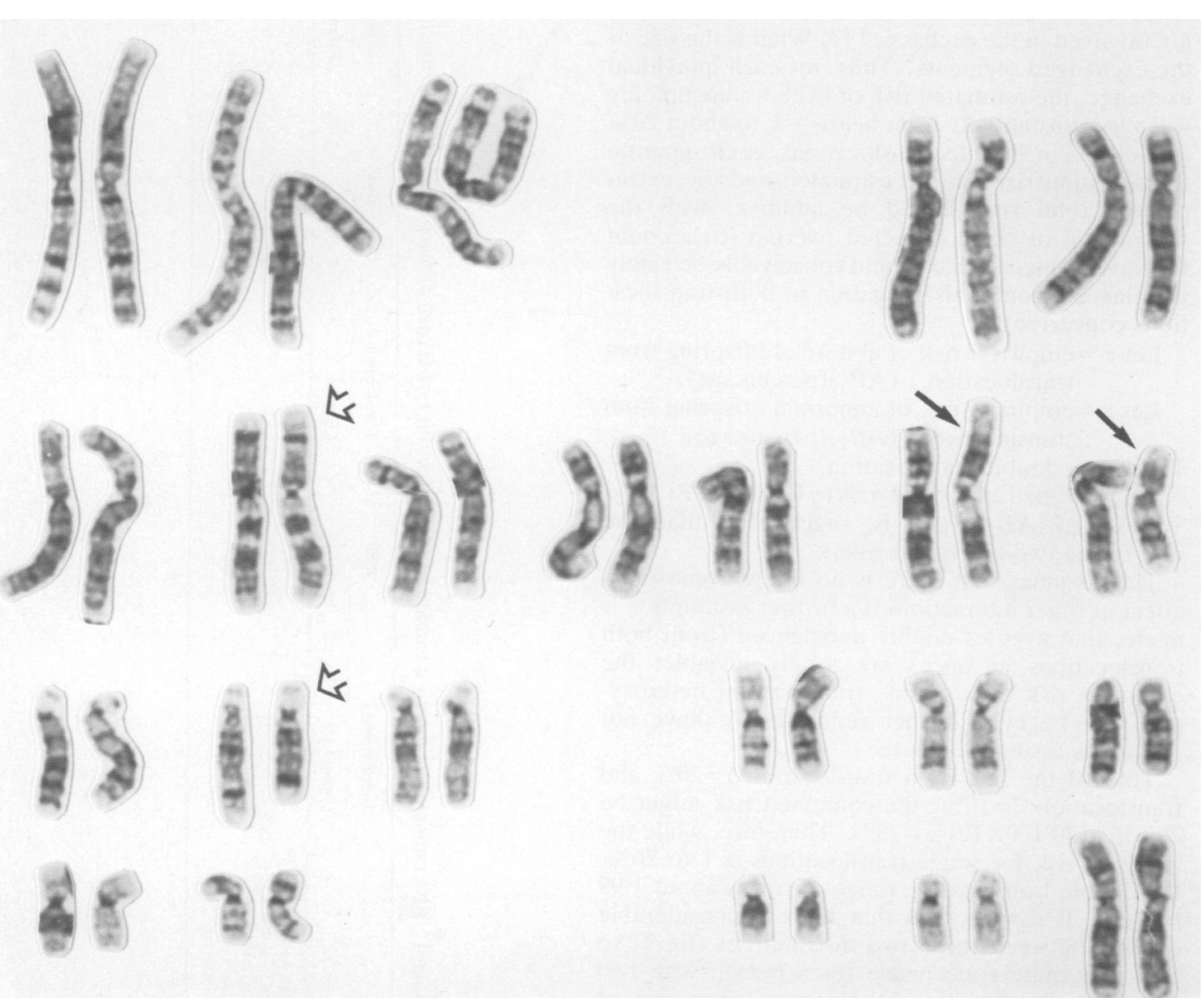

FIG 3 Karyotype from family 3, estimated to carry a very low risk of liveborn abnormality. 
probably have a lower imbalance tolerance while the former series have a relatively high imbalance tolerance, the extreme situations being that a few are seen as complete trisomies (for example, 13, 18, and 21$)$ or substantial deletions $(4 p-, 5 p-)$.

Some authors have suggested that the sex of the carrier parent influences empirical risk, ${ }^{22}{ }^{23}$ but this is not verified by the European collaborative study. ${ }^{19}$ Perhaps the most important single piece of information emerging from this collaborative study is that the empirical risk of having a viable abnormal child after a previous liveborn in a reciprocal translocation family is about $20 \%$, while it is only about $5 \%$ where there is another mode of ascertainment.

Keeping such observations in mind, it is possible to make a few generalisations and so estimate the risk of viable abnormality in a given translocation family, after asking three questions. (1) What is the mode of ascertainment? (2) Which chromosomes are involved in the exchange? (3) What is the size of the exchanged segments? Thus, for each individual exchange, the estimated risk of liveborn aneuploidy will vary substantially from below $1 \%$ to about $20 \%$ (table 2). For double translocations, each separate translocation risk can be estimated and the extrapolated total risk should be additive, with the subtraction of small expected overlap (to account for those gametes which could conceivably be viably imbalanced from malsegregation in both translocations concurrently).

Let $r_{1}=$ empirical risk of abnormal offspring from translocation $1\left(\mathrm{AB}_{1}\right)$ (percentage).

Let $r_{2}=$ empirical risk of abnormal offspring from translocation $2\left(\mathrm{AB}_{2}\right)$ (percentage).

Thus for a double translocation,

$\mathrm{r}_{\mathrm{c}}$ (combined empirical risk) $=\mathrm{P}\left\{\mathrm{AB}_{1}\right\}+\mathrm{P}\left\{\mathrm{AB}_{2}\right\}$

$-P\left\{A_{1}\right\} . P\left\{A_{2}\right\}$ (that is, slightly less than the sum of the two individual risks).

This assumes that there is no interchromosomal effect or other interaction. If a further assumption is made, that zygotes doubly unbalanced (from both translocations at once) are totally inviable, the empirical risk to a double translocation heterozygote can be even further reduced. We have not made this assumption here.

Thus, if the risk from translocation $1=20 \%$ and translocation $2=10 \%$, the combined risk might be $20+10-(20 / 100 \times 10) \%=28 \%$. Therefore, while the range of risk for single translocations is 1 to $20 \%$, the double translocation range of risk is about 1.99 to $36 \%$. It can be seen that there is considerable overlap between these two distributions (fig 2) so that it is quite conceivable for a person with two particular translocations to have a lower risk of producing a liveborn abnormal child than an unre-

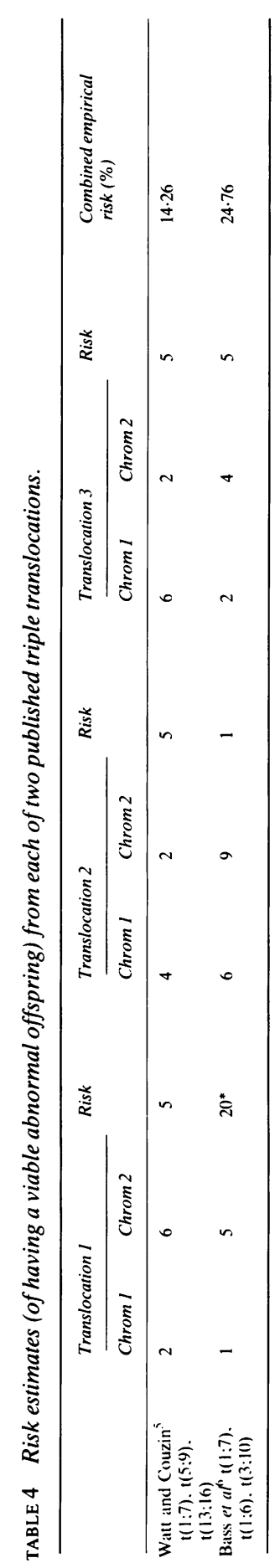


lated subject with only a single, comparatively 'high risk' translocation.

Table 3 estimates risk $\left(r_{c}\right)$, in this way, for each of the nine double translocations described. In particular, family 3 is estimated to have a very low risk of liveborn abnormality and could be given encouraging genetic counselling (fig 3 ), while the family described by Miller and Flatz ${ }^{8}$ is perhaps the most unfortunate.

The elemental rules can be easily extended to triple translocation families.

Thus, for a triple translocation

$r_{c}$ (combined empirical risk) $=P\left\{\mathrm{AB}_{1}\right\}+P\left\{\mathrm{AB}_{2}\right\}$ $+\mathrm{P}\left\{\mathrm{AB}_{3}\right\}-\left[\mathrm{P}\left\{\mathrm{AB}_{1}\right\} \cdot \mathrm{P}\left\{\mathrm{AB}_{2}\right\}+\mathrm{P}\left\{\mathrm{AB}_{2}\right\} \cdot \mathrm{P}\left\{\mathrm{AB}_{3}\right\}+\mathrm{P}\right.$ $\left.\left\{\mathrm{AB}_{1}\right\} . P\left\{\mathrm{AB}_{3}\right\}-\mathrm{P}\left\{\mathrm{AB}_{1}\right\} . \mathrm{P}\left\{\mathrm{AB}_{2}\right\} . \mathrm{P}\left\{\mathrm{AB}_{3}\right\}\right]$

It is interesting to note the difference between the theoretical risk quoted by Watt and Couzin 5 and the 'extrapolated empirical risk' in table 4 which is considerably lower and comes within the distribution range of single translocations.

The proposed method clearly has limitations and does not claim an accuracy of $98 \%$ like de Arce's elegant computer program, but merely offers a quick method of broadly assessing risk in rare situations, where the range of risk is very variable and where clinicians need to counsel with particular caution. Above all, it is worth remembering that double and triple translocation heterozygotes may be quite fertile and may have an empirical risk which does not exceed many of the standard single translocations.

The authors are grateful for the cytogenetic analysis done by Zoe Docherty, Julie Fleetwood, and Diane Butler on a few individual cases, for the clinical assistance of Dr Sarah Bundey and Dr Jack Insley, for the statistical advice given by Dr David Couzin, and for help with the pedigree of family 9 by Dr Elizabeth Boyd.

\section{References}

1 Bell EF, Warburton D. Two reciprocal translocations associated with microcephaly and retardation. J Med Genet 1977;14:141-2.

2 de Grouchy J, Lantmann F. Caryotype 46,XX,1q-;2q+,16q+ chez une enfant polymalformée. Ann Genet (Paris) 1968:11:129-31.

3 Hansen RG, Anderson RL. Rary JM. Double balanced autosomal translocation carrier $(6 ; 8)$, (13;14): a casc report. J Hered 1983:74:45()-2.

4 Bijlsma JB, de France HG, Bleeker-Wagemakers LM, Dijkstra PF. Double translocation $t(7 ; 12) t(2 ; 6)$. Heterozygosity in a family. Hum Genet 1978;40:135-47.
5 Watt JL, Couzin DA. De novo translocation heterozygote with three reciprocal translocations. J Med Genet 1983;20:385-8.

6 Bass HN, Sparkes RS, Lessner MF, Phoenix B, Bernar J. A family with three independant autosomal translocations associated with 7q32 $\rightarrow$ 7qter syndrome. J Med Genet 1985;22:59-63.

7 Bass HN, Sparkes RS. Two balanced translocations in three generations of a pedigree: $t(7 ; 10)(q 11 ; q 22)$ and $t(14 ; 21)$ (14qter $\rightarrow$ cen $\rightarrow 21$ qter). J Med Genet 1979;16:215-8.

8 Miller K, Flatz SD. Segregation of two independent chromosome translocations in one family. Hum Genet 1984;68:93-5.

9 de Grouchy J, Finaz C, Roubin M, Roy J. Deux translocations familiales survenues ensemble chez chacune de deux soeurs l'une equilibrée, l'autre trisomique partielle 10q. Ann Genet (Paris) 1972;15:85-92.

10 Mulcahy MT, Watson M. Prenatal diagnosis of a double heterozygote for two reciprocal translocations of familial origin. Prenat Diagn 1983;3:351-3.

1 Borgaonkar DS, Shaffer R, Albright R, Reed WC, Jackson LG. Repository of chromosomal variants and anomalies in man. Tenth listing. Philadelphia: Thomas Jefferson University, 1983.

12 Watt JL, Stephen GS. Lymphocyte culture for chromosome analysis. In: Human cytogenetics: a practical approach. Oxford: IRL Press, 1986:39-55.

${ }^{13}$ Rooney DE, Czepulkowski BH. Tissue culture methods in human cytogenetics. In: Human cytogenetics: a practical approach. Oxford: IRL Press, 1986:1-36.

14 ISCN (1978). An International System For Human Cytogenetic Nomenclature. New York: The National Foundation-March of Dimes, 1987.

15 Aurias A, Prieur M, Dutrillaux B. Systematic analysis of 95 reciprocal translocations of autosomes. Hum Genet 1978;45: 259-82.

16 Boué A, Boué J. Chromosome structural rearrangements and reproductive failure. Chromosomes Today 1981;7:281-90.

17 Daniel A. Structural differences in reciprocal translocations. Potential for a model of risk in RCP. Hum Genet 1979;51: 171-82.

18 Davis JR, Rogers BB, Aagaman M, Thies CA, Veomett IC. Balanced reciprocal translocations: risk factors for aneuploid segregant viability. Clin Genet 1985;27:1-19.

19 de Arce MA, Grace PM, McManus S. A computer model for the study of segregation in reciprocal translocation carriers. Application to 20 new cases. Am J Med Genet 1986;24:519-25.

20 Schwartz S, Palmer CG, Yu PL. Evaluation of factors differentiating translocations ascertained in couples with fetal wastage and translocations ascertained through an unbalanced carrier. Am J Hum Genet 1982;34:142A.

3i Bouć A, Gallano P. A collaborative study of the segregation of inherited structural rearrangements in 1356 prenatal diagnoses. In: Hamerton JL, Ferguson-Smith MA, eds. Collaborative studies in prenatal diagnosis of chromosome aberrations. Prenat Diagn special issuc 1984:4:45-68.

22 Hamerton JL. Human cytogenetics. Vol 1. General cytogenetics. New York, London: Academic Press, 1971.

23 Jacobs PA, Buckton KE, Cunningham C, Newton M. An analysis of the break points of structural rearrangements in man. J Med Genet 1974;11:65-8.

Correspondence and requests for reprints to Dr J L Watt, Regional Cytogenetics Unit, Birmingham Maternity Hospital, Edgbaston, Birmingham B15 2TG. 